\title{
Prediction of Naturally Fractured Reservoir Performance using Novel Integrated Workflow
}

\author{
Reda Abdel Azim \\ Chemical and Petroleum Engineering Department \\ American University of Ras Al Khaimah \\ Ras Al Khaimah, United Arab Emirates
}

\begin{abstract}
Generation of naturally fractured reservoir subsurface fracture maps and prediction its production potential are considered complex process due to insufficient data available such as bore hole images, core data and proper reservoir simulator model.

To overcome such shortcomings, the industry has relied on geo-statistical analyses of hard and soft data, which are often referred to as static data. This paper presents an integrated workflow that models and predicting fractured reservoirs performance, through the use of gradient-based inversion techniques and discrete fracture network modelling (DFN), which-through the inversion of well test data (i.e., dynamic data)-aims to optimise fracture properties and then predicting of the reservoir production potential. The first step in the workflow is to identify flow contributing fracture sets by analysing available core descriptions, borehole images, conventional log data and production data. Once the fracture sets are identified, the fracture intensity is statistically populated in the inter-well space. In the second step, 3D block-based permeability tensors are calculated based on flow through discrete fractures, and the fracture intensity is then propagated away from the wellbore, i.e., by relating to permeability tensors with fracture intensity. In the final step (fracture optimisation), the fracture properties are computed by DFN modelling, which includes distribution, orientation and geometry in different realisations. Fluid flow is simulated in these discrete fractures to estimate pressure change and pressure derivatives. The production rate associated with drill stem test that performed within this reservoir area has been successfully simulated using the optimised subsurface fracture map that has been generated from the first step.
\end{abstract}

Keywords-fractured reservoirs; production potential; fracture network map and finite element

\section{INTRODUCTION}

The characterization and predicting the performance of naturally fractured reservoirs are enormous challenges for oil and gas industry. Reservoir models that used to in the prediction of reservoir performance during the depletion optimization and field development planning processes must incorporate the effects of natural fractures in near the wellbore regions. Moreover, to predict their distribution in inter-well areas as well.

Distributing fracture properties methods that based on static data are presented extensively in the literature [1], [2], and [3]. Nevertheless, most of these geological models have failed to reproduce well production histories and capture the complex heterogeneity and anisotropy of the fracture system [4] and [5].

Since the 1970s, a significant progress has been made to generate a consistent methodology to characterise naturally fractured hydrocarbon and geothermal reservoirs by utilising well test and production data. This has been using static data and inversion techniques as stochastic algorithms, and gradient-based and streamline-based techniques [6], [7], [8], [9], [10], and [11].

Currently, three major approaches are used to simulate fluid flow through naturally fractured reservoirs, which include continuum, dual porosity/dual permeability, and flow through discrete fracture approaches. A review of these models can be found in the works of [12], [13] and [14] for continuum approach. [15], [16], [17], [18] and [19] for flow through discrete fracture approach.

In this paper, pressure transient data from a fractured basement reservoir offshore Vietnam has been used to evaluate the fracture map which is generated by statistical analysis of field data. In addition, a multiphase fluid flow simulator using finite element technique has been generated and used to evaluate the recovery potential of the naturally fractured reservoir under different driving mechanisms and to assess the optimised (generated) subsurface fracture map by comparing the predicted and history production data.

\section{GENERATION OF SUBSURFACE NETWORK FRACTURE MAP}

Object based simulation technique is used in generation of network fracture maps [20]. Fractures are treated as different objects and placed in the domain randomly. The number of fractures generated organized by fracture intensity and fractal dimension parameters.

\section{A. Fracture Intensity}

The fracture intensity is an important parameter to give an indication about the probability of fractures occurrence in a discrete fracture model [21]. The fracture intensity is defined as the number of fractures per unit bulk volume. The fracture intensity is calculated by dividing the studied into different grid blocks and fractures that cut each block are well-defined. Then, the number of these fractures divided by the bulk volume of the corresponding grid block. Fracture intensity map extracted from geological interpretations of reservoirs. Fracture intensity expressed as: 


$$
\text { FractureIntensity }=\frac{\sum_{i=1}^{N} \text { Area }}{\text { Volume }}
$$

Where, $\mathrm{N}$ is the total number of fractures that intersect the corresponding grid block.

\section{B. Fractal Dimension}

Fractal dimension is used to describe the self-similarity of discontinuous objects. This property is used in describing fracture characterization, which include fracture length, fracture growth, and branching in a fractured reservoir [22]. The fractal geometry concept relates the number of fractures ( $N_{\text {Rad }}$ ) to size ( $R a d$ ) by fractal dimension ( $D$ ) and proportionality constant ( $C$ ) through the following relationship:

$$
N_{\text {Rad }}=\frac{C}{\operatorname{Rad}^{D}}
$$

There are different methods used to calculate the fracture fractal dimension, which include box counting, index spectrum method [23] and area perimeter method. In this study, a box counting method used to determine the fractal dimension to generate discrete fracture network based on a comprehensive statistical study of core and logs data. The fracture system is contained in a square area of length $\left(L_{o}\right)$ and this area is divided into $L_{o}^{2} / l^{2}$ boxes of side length ( $l$ ) depending on the number of boxes $N(l)$ intersect with fractures or contain fractures (see Fig.1). $N(l)$ can be expressed as:

$$
N(l)=\frac{C}{l^{D}}
$$

By plotting logarithmic curve between number of boxes and $1 / l$, then fractal dimension $(D)$ value can be calculated from the slope as shown in (Fig.2).

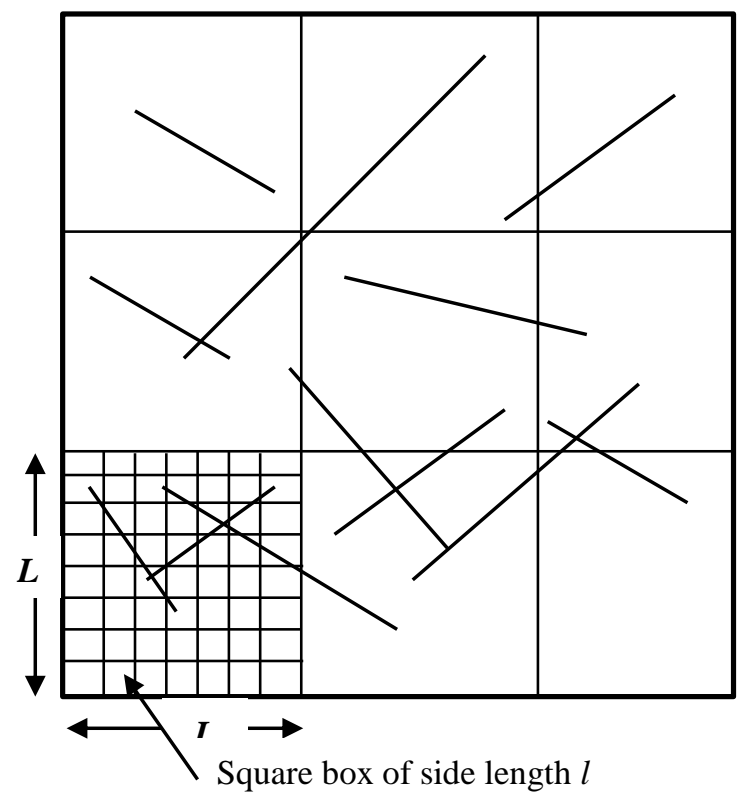

Fig. 1. Box counting method for solving fracture fractal dimension

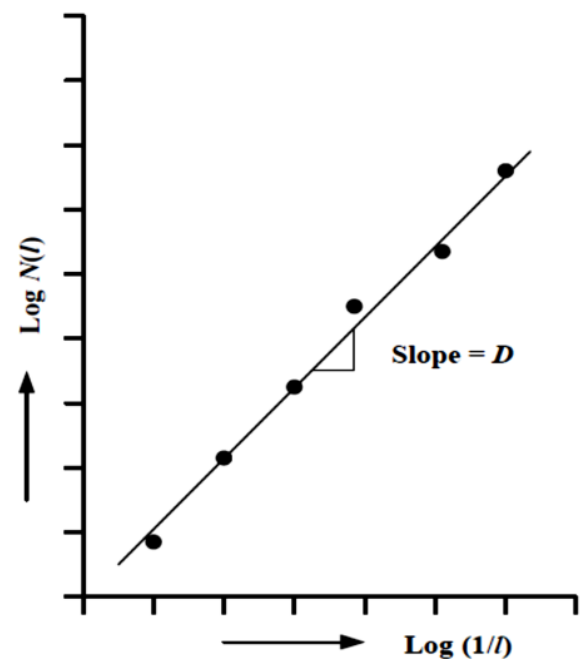

Fig. 2. Logarithmic plot for calculation fractal dimension using boxing counting method 


\section{DATA STATISTICAL ANALYSIS}

3D fractures that have been generated stochastically using Gaussian stochastic simulation in which each fracture feature is generated based on the random realisation and it continues until the total fracture intensity and fractal dimension of the studied area are met.

Data related to fracture properties and pressure transient obtained from [22] and presented in Table I and Fig. 3. Formation Image Logs are available and used in the generation of subsurface fracture map. The main permeable intervals are divided into three zones: (a) zone (1) from 668 to $690 \mathrm{~m}$; (b) zone (2) at $725 \mathrm{~m}$ and (c) zone (3) at approximately $760 \mathrm{~m}$. Zone (1) has the major flow contributor and the remaining production is contributed by zone (2) and zone (3) (see Fig.4). PL results have proved that the fracture aperture and permeability existing in zone (1) are very high compared to other zones

The fracture sets are defined based on fractures dip, length, and azimuth. The initial data of fracture length and dip angles range from $9 \mathrm{~m}$ to $60 \mathrm{~m}$ and $70^{\circ}$ to $90^{\circ}$ respectively, and the fracture aperture ranges from $0.004 \mathrm{~mm}$ to $0.04 \mathrm{~mm}$. Once the fracture set has been identified, it is used in the form of a fracture intensity plot.

Fig.5 shows the rose diagram for azimuth angles of the generated fractures, while (Fig.6) shows the histogram plot for dip angles of the generated fractures. The subsurface fracture map of the area (which include top, middle and bottom zone) around the tested well is generated by using the available field data of fracture intensity of $0.1 \mathrm{~m}-1$ [23] and the calculated fractal dimension of value $(D=1.25)$ and presented in (Fig.7).

Fig.8 shows the optimised block-based 3D permeability tensors of the reservoir while Fig.9 shows the optimized generated subsurface fracture map that will used in the assessment of fractured reservoir potential. Fig.10 shows a good match between simulated and actual pressure data.

TABLE I. RESERVOIR INPUTS DATA

\begin{tabular}{|c|c|}
\hline Property & Value \\
\hline Dimensions of the reservoir & $500 \mathrm{~m} \times 500 \mathrm{~m} \times 250 \mathrm{~m}$ \\
\hline Matrix permeability & $9.865 \times 10^{-16} \mathrm{~m}^{2}$ \\
\hline Matrix porosity & $2 \%$ \\
\hline Fracture aperture & $7.06 \times 10^{-3} \mathrm{~mm}$ \\
\hline Fractal dimension & 1.25 \\
\hline fracture intensity & $0.15 \mathrm{~m}^{-1}$ \\
\hline Initial reservoir pressure & $34.9 \mathrm{MPa}(5,063 \mathrm{psia})$ \\
\hline Injection pressure & $54.9 \mathrm{MPa}$ (7963.65psia) \\
\hline Fluid viscosity & $1.38 \mathrm{cp}$ \\
\hline Fluid compressibility & $10-8 \mathrm{MPa}^{-1}$ \\
\hline $\begin{array}{l}\text { Production time before shut } \\
\text { in (tp) }\end{array}$ & $72 \mathrm{hrs}$ \\
\hline flow rate (shut in) & $5571 \mathrm{bbl} / \mathrm{d}$ \\
\hline
\end{tabular}

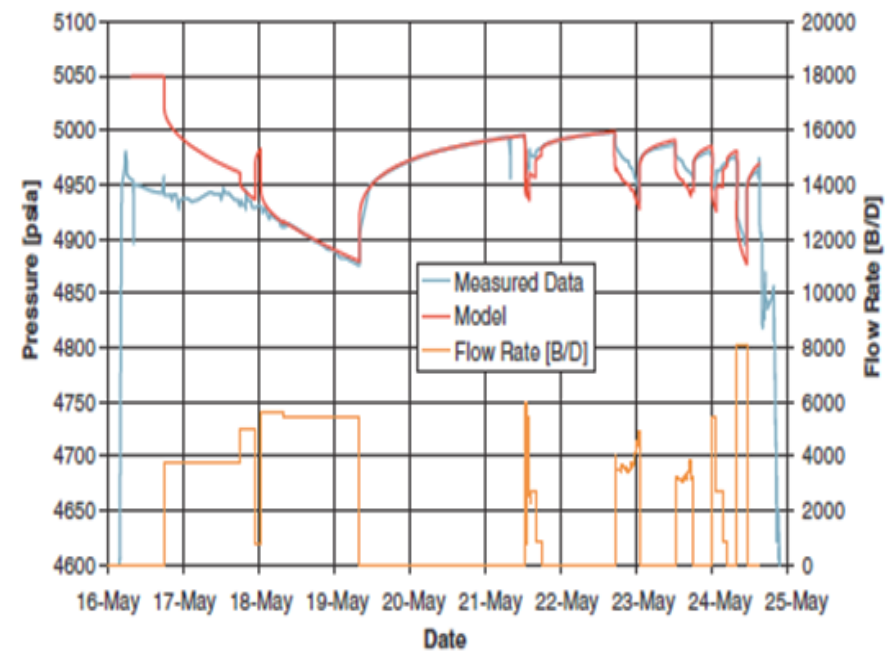

Fig. 3. Entire test history (DST test): measured and model data [22]; reprinted by permission of the Society of Petroleum Engineers)

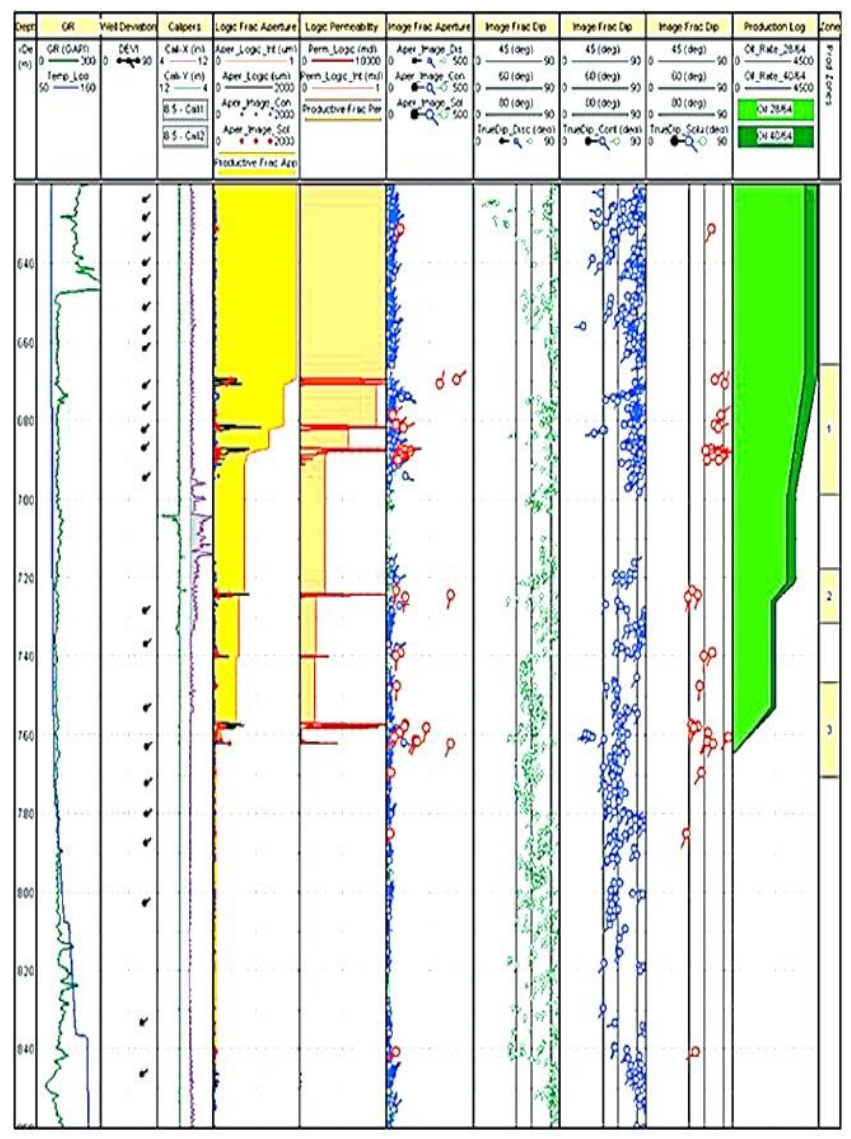

Fig. 4. Formation image and production logs for a typical basement well used for generating the discrete fracture network in the studied area ([22]; reprinted by permission of the Society of Petroleum Engineers) 


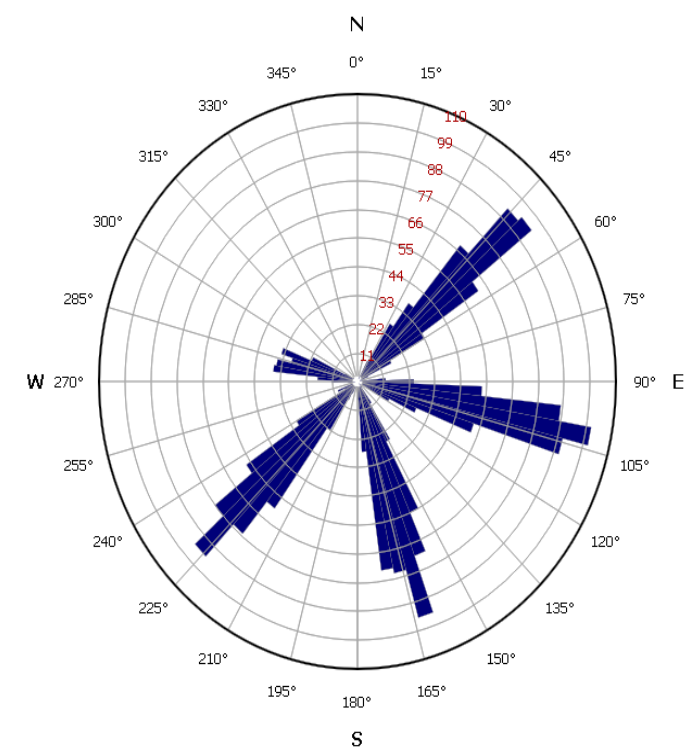

Fig. 5. Rose diagram of fractures azimuth angle

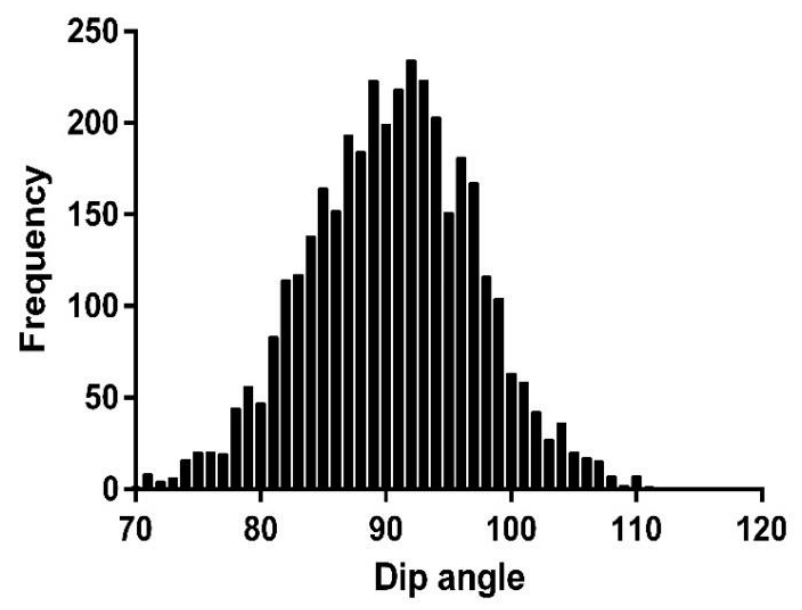

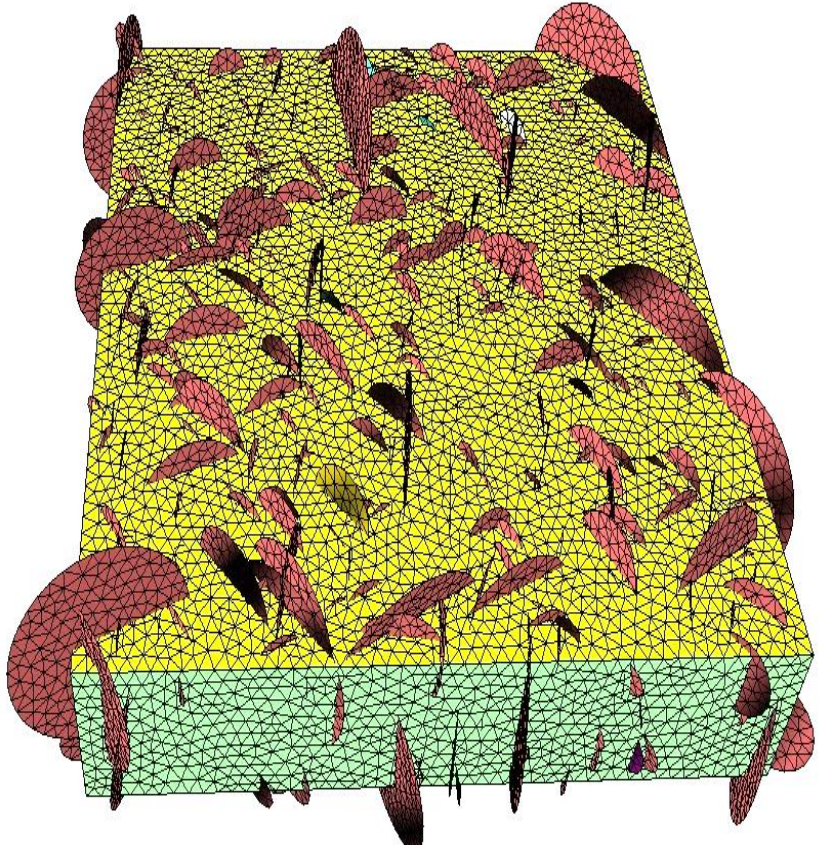

Fig. 7. 3D fracture map generated using object based model

Fig. 6. Histogram plot of fractures dip angles (angles are ranging from $70^{\circ}$ to $110^{\circ}$ degrees). The plot is following the normal distribution function 


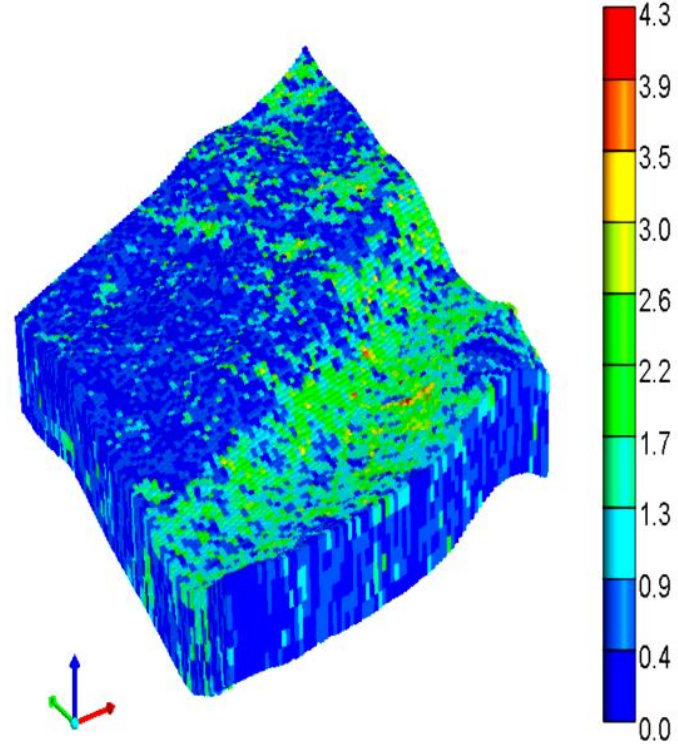

(a)

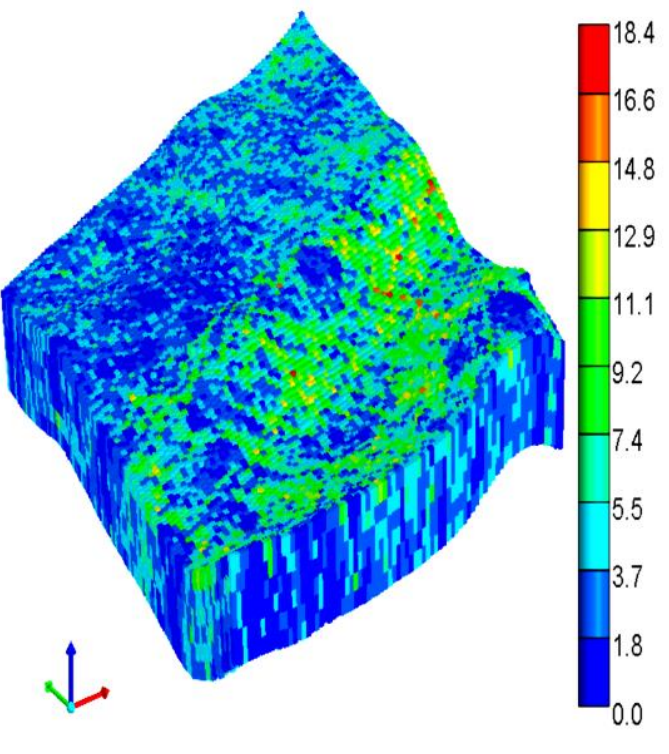

(b)

Fig. 8. (a) Initial block based RMS (Root Mean Square) permeability tensor and (b) Optimized block based RMS (Root Mean Square) permeability tensor
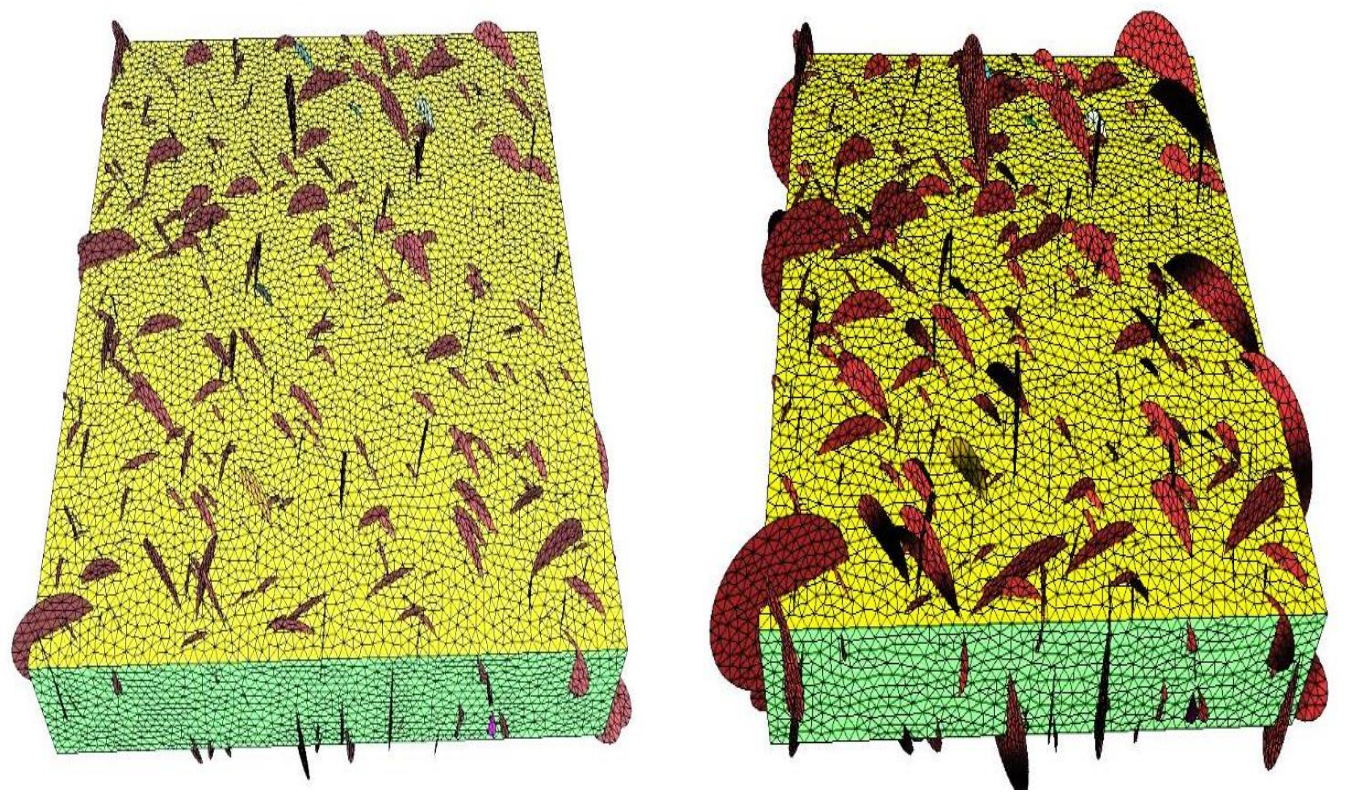

Fig. 9. (a) 3D optimized fracture map and (b) initial 3D fracture map generated in first realization

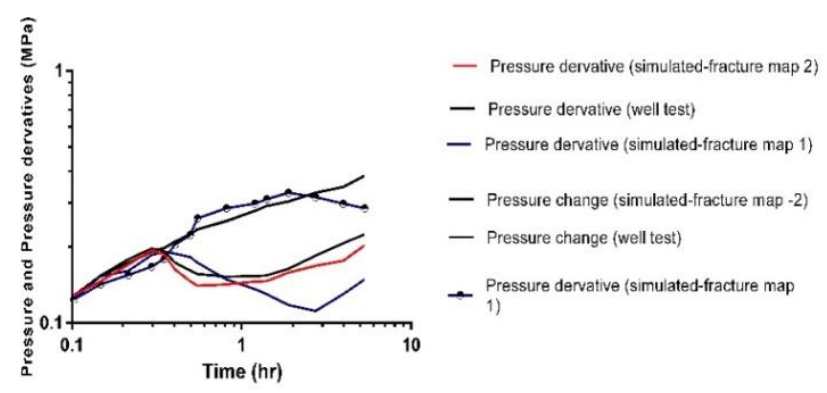

\section{DEPLETION SCENARIO}

First, the drawdown test that was conducted in this reservoir is simulated for a period of 3 days of oil production. A production constraint of constant flow rate of $5571 \mathrm{bbls} / \mathrm{d}$ is used to predict the drawdown pressure. From the results, it has been shown that the simulated well flowing bottom hole pressure before shut in (after $72 \mathrm{hrs}$ of oil production) is 4900psi which is very close to measured pressure (4880psi) obtained from DST (Fig.3). Then the evaluation of the production potential of this reservoir is performed under depletion drive mechanism using data in Table II. The

Fig. 10. Pressure change and pressure derivatives, this plot is produced based on hybrid approach 
producing well is slanted and intersected with a high fracture intensity blocks.

Fig.11 shows the pressure distribution after 3 days of oil production. Fig.12 shows the oil production rate for the producing well at constant bottom hole flowing pressure (31.8MPa). As shown in the figure that a sudden changes in oil production rate occurred and later the rate becomes steady. This is mainly due to the fact that at the beginning of the production process the fluids flow mainly through the fractures, which caused a sudden drop in wellbore pressure. Then, the matrix starts to feed the fractures network by fluid. During this flow period the oil production rate at the wellbore becomes very low and pressure starts to drop slowly. The calculated oil in place for the studied reservoir is $4.2 \mathrm{MM}$ bbl and the oil recovery for case of production under depletion drive mechanism is $1.25 \%$.

TABLE II. RESERVOIR INPUT PARAMETERS USED FOR ESTIMATION OF OIL RECOVERY UNDER DIFFERENT DRIVING MECHANISMS

\begin{tabular}{|l|c|}
\hline \multicolumn{1}{|c|}{ Parameter } & Value \\
\hline Reservoir dimensions & $\begin{array}{c}500 \mathrm{~m} \times 500 \mathrm{~m} \\
\times 250 \mathrm{~m}\end{array}$ \\
\hline Fracture aperture $(\mathrm{mm})$ & $7.06 \times 10^{-3}$ \\
\hline Matrix porosity & $2 \%$ \\
\hline Matrix permeability $(\mathrm{mD})$ & 0.0095 \\
\hline Initial reservoir pressure $(\mathrm{MPa})$ & $34.9(5060 \mathrm{psi})$ \\
\hline Bubble point pressure $(\mathrm{MPa})$ & $31.7(4597 \mathrm{psi})$ \\
\hline $\begin{array}{l}\text { Well Bottom hole pressure }(\mathrm{MPa}) \\
\text { (production) }\end{array}$ & $31.8(4612 \mathrm{psi})$ \\
\hline Injection pressure $(\mathrm{MPa})$ & 44.2 \\
\hline Initial water saturation & 0.3607 \\
\hline Oil viscosity $(\mathrm{cp})$ & 1.37 \\
\hline Oil Density $\left(\mathrm{kg} / \mathrm{m}^{3}\right)$ & 899 \\
\hline Formation volume factor & 1.3312 \\
\hline Reservoir fluid compressibility $\left(\mathrm{MPa}^{-1}\right)$ & $10^{-5}$ \\
\hline Horizontal stresses $(\mathrm{min} \& \mathrm{max})\left(\mathrm{MPa}^{3}\right.$ & $33.1(4800 \mathrm{psi})$ \\
\hline Vertical stress $(\mathrm{MPa})$ & $41.3(5990 \mathrm{psi})$ \\
\hline & 42 \\
\hline Young's modulus $(\mathrm{GPa})$ & 0.28 \\
\hline Poison ratio & 2800 \\
\hline Rock density $\left(\mathrm{kg} / \mathrm{m}^{3}\right)$ & 0.1 \\
\hline Wellbore radius $(\mathrm{m})$ & \\
\hline
\end{tabular}

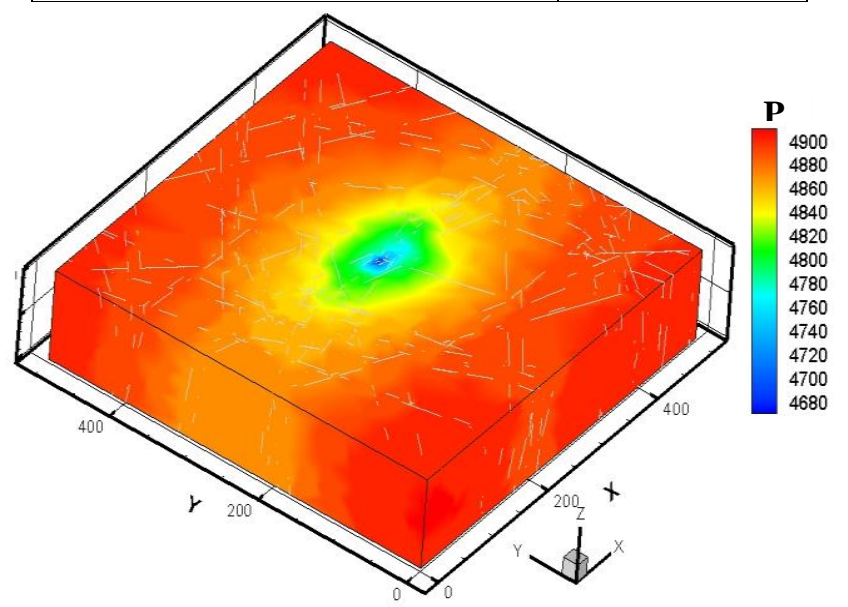

Fig. 11. Reservoir pore pressure distribution after 3 days of oil production with Pinit=34.9MPa, Pprod=31.8MPa $\sigma \mathrm{H}=33.1 \mathrm{MPa}, \sigma \mathrm{h}=33.1 \mathrm{MPa}, \sigma \mathrm{v}$ $=41.3 \mathrm{MPa}$ (depletion scenario)

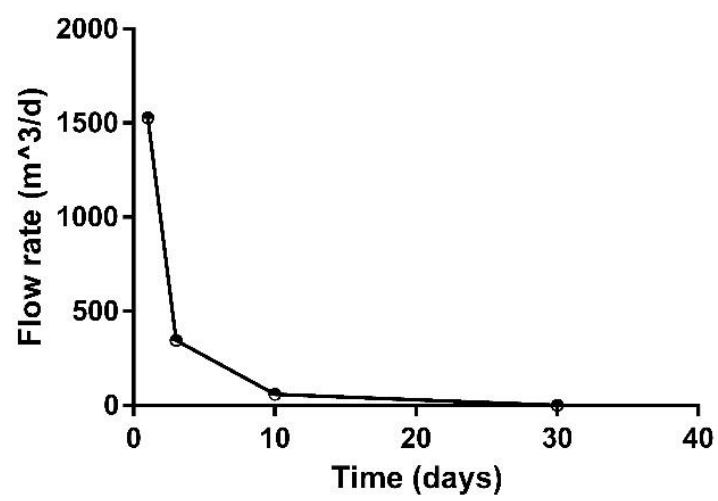

Fig. 12. Oil production rate under depletion drive mechanism with Pinit=34.9MPa, Pprod=31.8MPa $\sigma \mathrm{H}=33.1 \mathrm{MPa}, \sigma \mathrm{h}=33.1 \mathrm{MPa}, \sigma \mathrm{v}=41.3 \mathrm{MPa}$ (depletion scenario)

\section{WATER INJECTION SCENARIO}

Injection of water into the reservoir started when the reservoir pressure is depleted. In this scenario, an inverted five spot pattern is used in which four producers are placed at the reservoir corners and one injector at the centre. Injectors and producers used in this case are vertical wells. Water is injected into the bottom of basement reservoir and oil produced from the reservoir top zone.

Fig.13 shows the oil production rate with time. As can be seen from (Fig.12) that the oil rate is decreasing sharply at the first 10 days of oil production and then the decreasing rate becomes slower. This attributed to the contribution of the injected water in supporting the reservoir pressure. However, the amount of injected water is not enough to compensate the production at the beginning of production process. Fig.14 shows that water cut production rate is very low until 10 days (time for water breakthrough) and then the increasing rate increasing rapidly. This is mainly due to the forming of water buffer near injection wells as a result of water injection at high injection rate. Thus, the water at the beginning of the injection process tends to stay near the injection wellbore region and form artificial water buffers. With continuous of water injection, large water buffers are generated and forming initially water/oil contact. Then, water starts to move upward by following the vertical direction, which resulted in increasing of water cut rate at later stages. Moreover, Fig.15 shows how history data of well (1) has been simulated successfully.

There are two groups of wells describe the dynamics of water cut production within the studied basement reservoir. The first group with rapidly increasing of water cut (well 2\#, \#3 and \#4). In these wells (well \#2, \#3 and \#4), water cut curves have almost vertical trends which explain that these wells are intersected with high fracture intensity blocks (see Fig.15). The second group is a single well (well 1\#) with low water cut due to low fracture intensity blocks surround the well.

In order to decrease the water production in this area, the bottom perforation of producing zones has to be shut or isolated. Therefore, in $2^{\text {nd }}$ scenario, the bottom section of the 
four producers is shut (about $20 \mathrm{~m}$ ) and the oil is produced from the upper perforated intervals (this is applied after 25 days of oil production). Fig.16 and Fig.17 show the water cut and oil production after shutting of the bottom perforations respectively. As can be seen from these figures that the water cut rate (for the four producers) increases till 25 days and then starts to decrease (see Fig.16). In addition, oil production rate (for the four producers) decreases sharply till end of 25 days, and then rates turn out to be steady (see Fig.17). The oil recovery in this scenario by end of 3 months of water injection is $40 \%$.

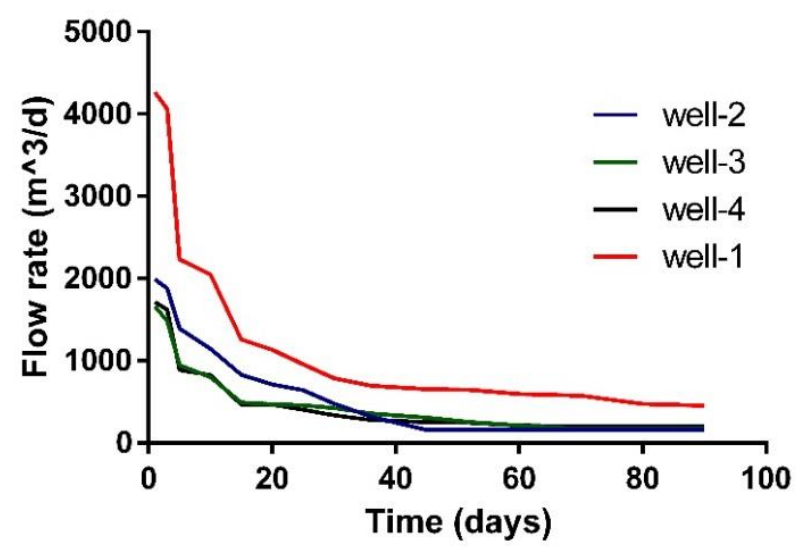

Fig. 13. Oil production rate under water flooding mechanism with $P_{\text {init }}=34.9 \mathrm{MPa}, \mathrm{P}_{\text {inj }}=44.2 \mathrm{MPa}, \mathrm{P}_{\text {prod }}=31.8 \mathrm{MPa} \sigma_{\mathrm{H}}=33.1 \mathrm{MPa}, \sigma_{\mathrm{h}}=33.1 \mathrm{MPa}, \sigma_{\mathrm{v}}$ $=41.3 \mathrm{MPa}\left(1^{\text {st }}\right.$ scenario $)$

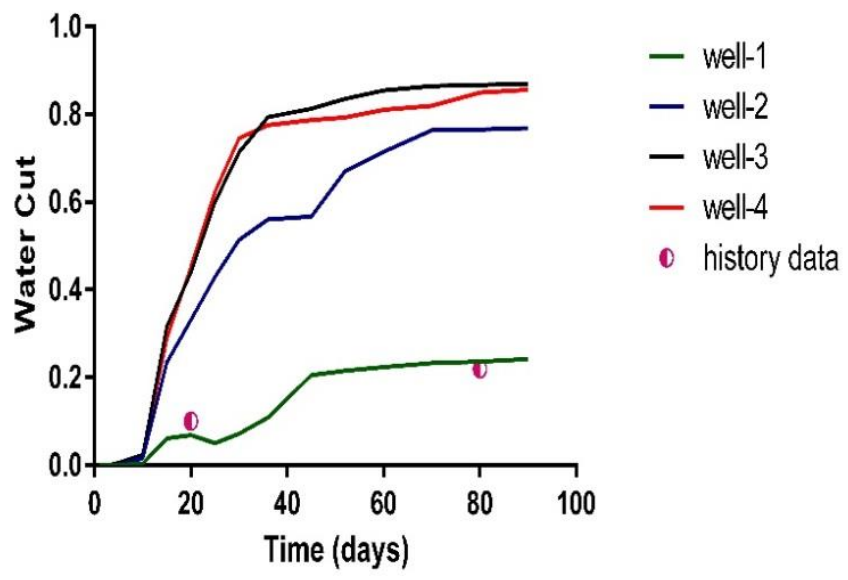

Fig. 14. Water cut at the production wells with $\mathrm{P}_{\text {init }}=34.9 \mathrm{MPa}, \mathrm{P}_{\text {inj }}=44.2 \mathrm{MPa}$, $\mathrm{P}_{\text {prod }}=31.8 \mathrm{MPa} \sigma_{\mathrm{H}}=33.1 \mathrm{MPa}, \sigma_{\mathrm{h}}=33.1 \mathrm{MPa}, \sigma_{\mathrm{v}}=41.3 \mathrm{MPa}$. $\left(1^{\mathrm{st}}\right.$ scenario $)$

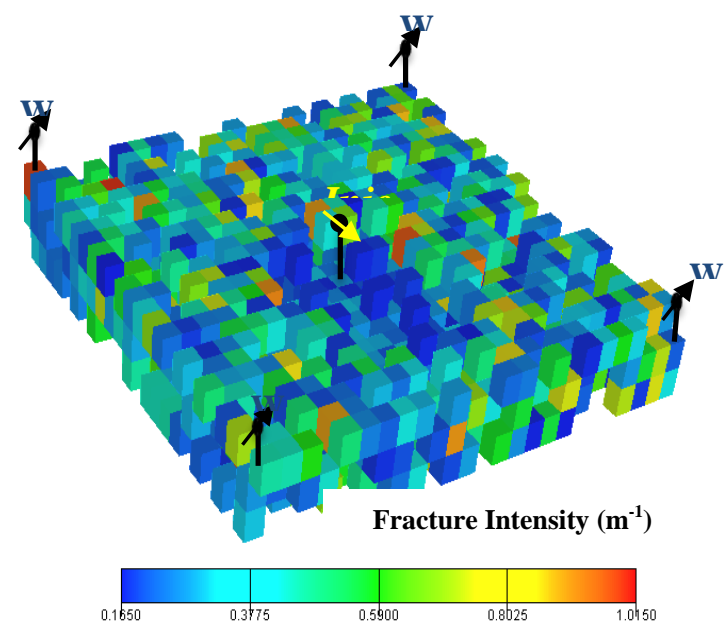

Fig. 15. Wells location and block based fracture intensity map for the entire reservoir region obtained by using the optimized block based permeability tensors the map is cut off by $0.165 \mathrm{~m}^{-1}$ )

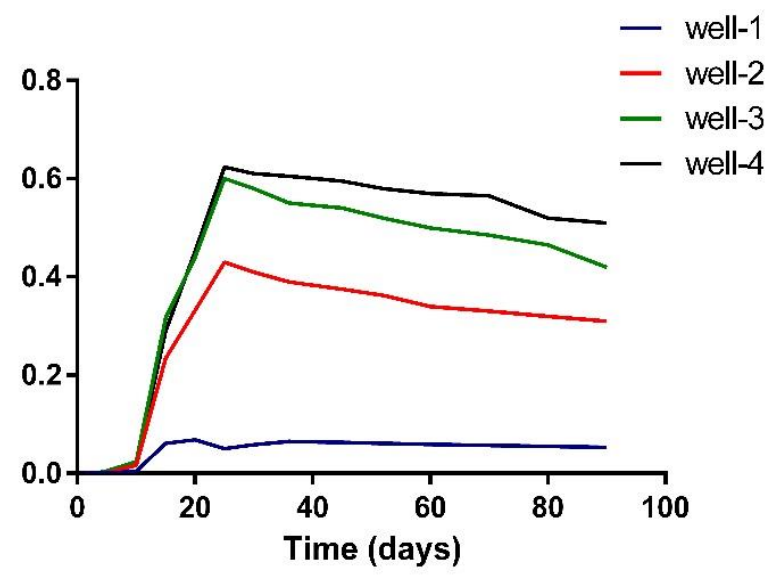

Fig. 16. Water cut at the production wells with Pinit=34.9MPa, Pinj=44.2MPa, Pprod=31.8MPa $\sigma_{\mathrm{H}}=33.1 \mathrm{MPa}, \sigma_{\mathrm{h}}=33.1 \mathrm{MPa}, \sigma_{\mathrm{v}}=41.3 \mathrm{MPa}$. ( $2^{\text {nd }}$ scenario)

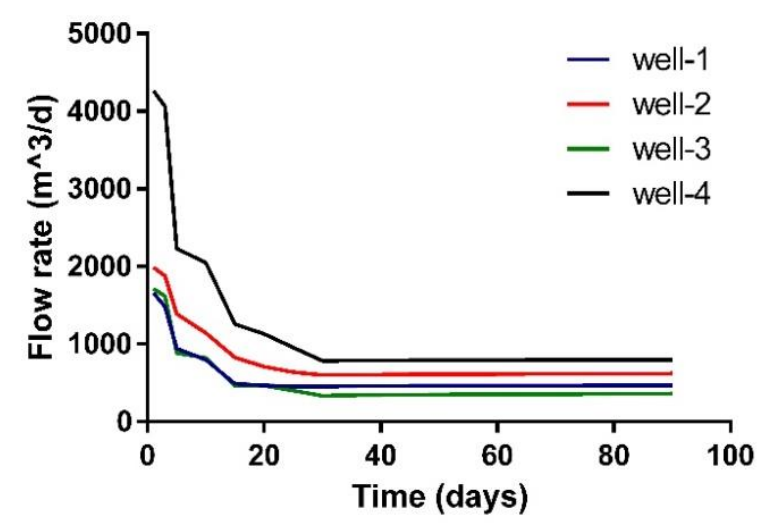

Fig. 17. Oil production rate under water flooding mechanism with $P_{\text {init }}=34.9 \mathrm{MPa}, \mathrm{P}_{\text {inj }}=44.2 \mathrm{MPa}, \mathrm{P}_{\text {prod }}=31.8 \mathrm{MPa} \sigma_{\mathrm{H}}=33.1 \mathrm{MPa}, \sigma_{\mathrm{h}}=33.1 \mathrm{MPa}, \sigma_{\mathrm{v}}$ $=41.3 \mathrm{MPa}\left(2^{\text {nd }}\right.$ scenario $)$ 


\section{CONCLUSION}

In this paper, the governing equations of single-phase fluid flow are derived from mass and momentum balance equations. These equations are used to simulate flows in discrete fractures and porous matrix media. The single-phase fluid flow is used as a forward fluid flow model in the history matching of well test data, and a gradient-based algorithm is used to optimise a sub-surface fracture map. The results show that the simulated well test data from the first realisation of fractures vary significantly $(>2 \%)$ from the well test data.

A successful waterflooding can be achieved in naturally fractured reservoirs by understanding the geological characterization and fracture network system. Injection of water at the bottom section of these reservoir types will generate a large scale of water buffer helps in maintaining the reservoir pressure and significantly increase the oil recovery factor. Injector location sits in the reservoir centre (forming the five spot patterns) that concluded from the experience of developing the water flooding process in such reservoir types (Dang et al., 2011) and shutting the bottom perforations near water/oil contact tend to increase the reservoir sweep efficiency and the oil recovery factor.

\section{ACKNOWLEDGMENT}

The author would like to thank University of New South Wales and oil and gas Company India for supporting this research project.

\section{REFERENCES}

[1] Will, R., Archer, R. A., and Dershowitz, W. S., 2005, Integration of seismic anisotropy and reservoir performance data for characterization of naturally fractured reservoirs using discrete feature network models: Society of Petroleum Engineers Reservoir Evaluation \& Engineering Journal, 8(02), 132-142.

[2] Doonechaly, N. G., and Rahman, S., 2012, 3D hybrid tectono-stochastic modeling of naturally fractured reservoir: Application of finite element method and stochastic simulation technique: Tectonophysics, 541, 4356.

[3] Abdel Azim, R., G. D., Nima, Rahman, Sheik S, Tyson, Stephen, and Regenauer-Lieb, Klaus, 2014, 3D Poro-Thermo-Elastic Numerical Model for Analysing Pressure Transient Response to Improve the Characterization of Naturally Fractured Geothermal Reservoirs: Geothermal Resources Council, 38, 907-915.

[4] Ouenes, A., Robinson, G., and Zellou, A. M., 2004, Impact of Pre-stack and Post-stack Seismic on Integrated Naturally Fractured Reservoir Characterization: Society of Petroleum Engineers Asia Pacific Conference on Integrated Modelling for Asset Management. Society of Petroleum Engineers.

[5] Efendiev, Y., Datta-Gupta, A., Ginting, V., Ma, X., and Mallick, B., 2005, an efficient two-stage Markov chain Monte Carlo method for dynamic data integration: Water Resources Research, 41(12).

[6] Chen, W. H., Gavalas, G. R., Seinfeld, J. H., and Wasserman, M. L, 1974, A new algorithm for automatic history matching: Society of Petroleum Engineers Journal, 14(6), 593-
Chavent, G. M., Dupuy, M., and Lemonnier, 1975, History Matching by Use of Optimal Control Theory: Society of Petroleum Engineers Journal, 15(1), 74-86.

[7] Landa, J., Horne, R., Kamal, M., and Jenkins, C., 2000, Reservoir characterization constrained to well-test data: a field example: Society of Petroleum Engineers Reservoir Evaluation \& Engineering, 3(04), 325334.

[8] Zhang, F., and Reynolds, A. C.,2002, Optimization algorithms for automatic history matching of production data: 8th European Conference on the Mathematics of Oil Recovery.

[9] Liu, Ning and Oliver, D. S., 2004, Automatic history matching of geologic facies: Society of Petroleum Engineers Journal, 9(04), 429-436.

[10] Gang, T., and Kelkar, M. G.,2006, Efficient history matching in naturally fractured reservoirs: Society of Petroleum Engineers /DOE Symposium on Improved Oil Recovery.

[11] Lough, M. F., Lee, S. H.,and Kamath, J.,1996, A new method to calculate the effective permeability of grid blocks used in the simulation of naturally fractured reservoirs: Society of Petroleum Engineers annual technical conference

[12] Gupta, A., Avila, R., and Penuela, G, 2001, An integrated approach to the determination of permeability tensors for naturally fractured reservoirs: Journal of Canadian Petroleum Technology, 40(12), 43-48.

[13] Park, Y., Sung, W., and Kim, S.,2002, Development of a FEM reservoir model equipped with an effective permeability tensor and its application to naturally fractured reservoirs: Energy sources, 24(6), 531-542.

[14] Choi, E., Cheema, T., and Islam, M.,1997, A new dual-porosity/dualpermeability model with non-Darcian flow through fractures: Journal of Petroleum Science and Engineering, 17(3), 331-344.

[15] Pride, S. R., abd Berryman, J. G., 2003, Linear dynamics of doubleporosity dual-permeability materials. I. Governing equations and acoustic attenuation: Physical Review E, 68(3), 036603.

[16] Gong, B., Karimi-Fard, M., and Durlofsky, L. J., 2008, Upscaling discrete fracture characterizations to dual-porosity, dual-permeability models for efficient simulation of flow with strong gravitational effects: Society of Petroleum Engineers Journal -, 13(1), 58.

[17] Karimi-Fard, M., Durlofsky, L., and Aziz, K., 2004, An efficient discrete-fracture model applicable for general-purpose reservoir simulators: Society of Petroleum Engineers Journal, 9(02), 227-236.

[18] Reichenberger, V., Jakobs, H., Bastian, P., and Helmig, R.,2006, A mixed-dimensional finite volume method for two-phase flow in fractured porous media:Advances in Water Resources, 29(7), 10201036.

[19] Abdelazim, R., and Rahman, S. S., 2016, Estimation of Permeability of Naturally Fractured Reservoirs by Pressure Transient Analysis: An Innovative Reservoir Characterisation and Flow Simulation: Journal of Petroleum Science and Engineering.

[20] Tran, N. H., Chen, Z., and Rahman, S. S., 2006, Integrated conditional global optimisation for discrete fracture network modelling: Computers \& Geosciences, 32(1), 17-27.

[21] Farag, S. M., Mas, C., Maizeret, P.-D., Li, B., and Le, H. V,2010, An integrated workflow for granitic basement reservoir evaluation: SPE Reservoir Evaluation \&

[22] Bour, O., Davy, P., Darcel, C., and Odling, N.,2002,A statistical scaling model for fracture network geometry, with validation on a multiscale mapping of a joint network (Hornelen Basin, Norway): Journal of Geophysical Research: Solid Earth (1978-2012), 107(B6), ETG 4-1ETG 4-12. 